\title{
Regime switching based portfolio selection for pension funds
}

\author{
Karl Frauendorfer *, Ulrich Jacoby, Alvin Schwendener \\ University of St. Gallen, Switzerland Institute for Operations Research and Computational Finance (iorcf), \\ Bodanstrasse 6, CH-9000 St. Gallen, Switzerland
}

Available online 16 February 2007

\begin{abstract}
This paper shows how a mean variance criterion can be applied to a multi period setting in order to obtain efficient portfolios in an asset and liability context. The optimization model allows for rebalancing activities, transaction costs, stochastic volatilities for both assets and liabilities. Furthermore, a general framework for the projection of pension fund liabilities as well as for the generation of asset returns is given. In a further step the dynamics of the liability maturity structure is modeled as customized index, whose volatility and correlation with asset returns become integral components of the applied regime switching approach. The numerical results illustrate the diversification of the assets and its risk return pattern in dependency of the liability dynamics.

(c) 2007 Elsevier B.V. All rights reserved.
\end{abstract}

JEL classification: G11; G15; G23; G32; C53; C61

Keywords: Portfolio management; Dynamic asset allocation; Stochastic multistage programming; Regime switching; Modeling of pension fund liabilities; Projection of the funding ratio

\section{Introduction}

The management of a pension fund is especially characterized by its guaranteed long term obligations that are usually protected either by law or by the underlying insurance policy. The funding of the fund's pension plans or rather its liabilities is effected by the

\footnotetext{
${ }^{*}$ Corresponding author. Tel.: +41712242101.

E-mail addresses: karl.frauendorfer@unisg.ch (K. Frauendorfer), ulrich.jacoby@unisg.ch (U. Jacoby), alvin.schwendener@unisg.ch (A. Schwendener).
} 
contributions of the insurees, their sponsoring firm and moreover by the return on the invested capital. Due to the long term investment horizon the return on the invested capital becomes a decisive element in funding a pension plan. In a defined benefit framework the return on the invested capital should therefore pace out the technical interest rate whereas in a defined contribution framework the return should pace out at least the guaranteed minimal return.

Unlike these (usually) guaranteed elements of any retirement plan, the return on the pension fund's asset allocation is not guaranteed. The observable stochastic volatilities on financial markets therefore necessitate a suitable Asset and Liability Management (ALM) for pension funds to safeguard the pension claims of the beneficiaries. In this context, the main task of any pension fund manager lies in the sustainable funding of the pension liabilities as well as in securing the payments of benefits to the beneficiaries. Hence, a firm implementation of sophisticated quantitative methods and concepts is indispensable in order to tackle the uncertainties that occur with any committed investment. Prominent models challenging this complex task can be found in the field of stochastic programming; like for example in Cariño et al. (1998), Mulvey and Ziemba (1998), Consigli and Dempster, 1998, Pflug and Swietanowski (2000), Mulvey and Shetty (2004), Drijver (2005), Zenios and Ziemba (2006) or Hilli et al. (in press).

This paper is structured as follows. In Section 2, a sophisticated model to project the liabilities of a pension fund will be briefly sketched. In Section 3, a regime switching model to estimate the expected returns of the pension fund's assets categories will be derived. Section 4 captures the key optimization problem in a way strategic asset allocation process allows to take the liability dynamic into account. It will be shown in Section 5 that the careful attention of the correlation structure between assets and liabilities, by means of the regime switching approach, will have a significant impact on the efficient asset allocation and therefore on the risk profile of the whole pension plan.

\section{Modeling pension fund liabilities}

The main purpose of a pension fund's asset allocation is to ensure the payments of well defined pension benefits to the insurees at well specified dates. In this connection, a detailed knowledge of the liability structure is a precondition for any successful ALM. In the following, a multi-period model predicting pension fund liabilities (either for defined benefit or defined contribution schemes) will be introduced.

The future development of pension fund liabilities is mainly driven by two factors: the evolvement of the population of insurees as well as by the growth of the insurees' future wages and accordingly their benefits. Concerning the projection of the population, the authors propose a multi-period Markov-chain framework, whereas future wages and benefits are modeled with appropriate stochastic processes. The following Fig. 1 shows the main principle of this approach (see also Koller, 2000).

The actuarial state of an insuree shall be described by the stochastic process $X$ with $X_{t}(\omega) \in S$. The underlying insurance policy defines for every actuarial state of the insuree the financial obligation due to the pension fund. The future pension fund liabilities are then derived by the so called contractual functions that are given by the underlying insurance policy and define for every possible actuarial state of the insuree the resulting financial obligation for the pension fund. In Fig. 1, these contractual functions are labeled with $a_{i j}(t)$, respectively, $a_{i i}(t) . a_{i i}(t)$, e.g., describes the function or rather the payment in case the 


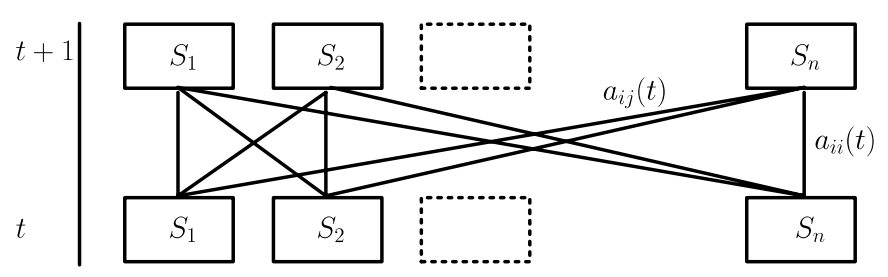

Fig. 1. State space, transitions in $t, t+1$.

insuree will remain in the same actuarial state also in the following period. $a_{i j}(t)$ contrariwise, describes the function in case the insuree will switch from state $i$ to state $j$ in the following period.

The flexibility of this approach allows to model the complete life-cycle of every insuree of a pension fund and to derive the amount of liabilities for the whole pension fund for every $t \in T$. The resulting liability-trajectories will then - at a later stage, respectively after an appropriate discounting - be an input to the optimization problem in Section 4. In fact, the pension-fund specific modeling of the liabilities, respectively the appropriate discounting will result in a customized liability index that will explicitly be incorporated in the modeling of the scenario tree of the optimization problem. Its volatility and correlations with assets returns become integral part of the regime switching model (see also Sections 3 and 4).

The following Fig. 2 shows a set of possible transits for a population of insurees of a pension fund whereby the following states are taken into consideration (see also Jacoby, 2005):

- internal, active members (A),

- disabled retirees (I),

- widows, widowers (W),

- external, active members (E),

- retirees $(\mathrm{R})$,

- beneficiaries of orphan's pension $(\mathrm{K})$,

- members dropped out without any claim (O).

$p^{\mathrm{AI}}$, for example, describes the probability of an internal active member to get disabled between $t$ and $t+1 . p^{\mathrm{RW}}$, for example, describes the probability of a retiree to decease between $t, t+1$ and to leave behind a widow. The calculation of these different transition probabilities is based on the corresponding actuarial life tables for males and females. A very detailed essay in deriving the transition probabilities shown in Fig. 2 can be found in Jacoby (2005). While the population scheme is modeled by Markov-processes, the future growth rates of wages and pensions as well as the guaranteed minimal return rate for defined benefit systems are modeled with a set of appropriate Ornstein-Uhlenbeck processes:

$$
\mathrm{d} X_{t}=\kappa\left(\mu-X_{t}\right) \mathrm{d} t+\sigma \mathrm{d} W_{t}+v \mathrm{~d} J_{t} .
$$

The Ornstein-Uhlenbeck process in Eq. (1) has been extended by a poisson jump process. In fact, the process is similar to the one used by Merton (1976). Formulated this way, it allows to model individual salary developments for each plan member over time. It is further assumed that the individual salary development is mainly driven by the strategy of the plan sponsor than by some macroeconomic factors. The term $v \mathrm{~d} J_{t}$ shall represent 


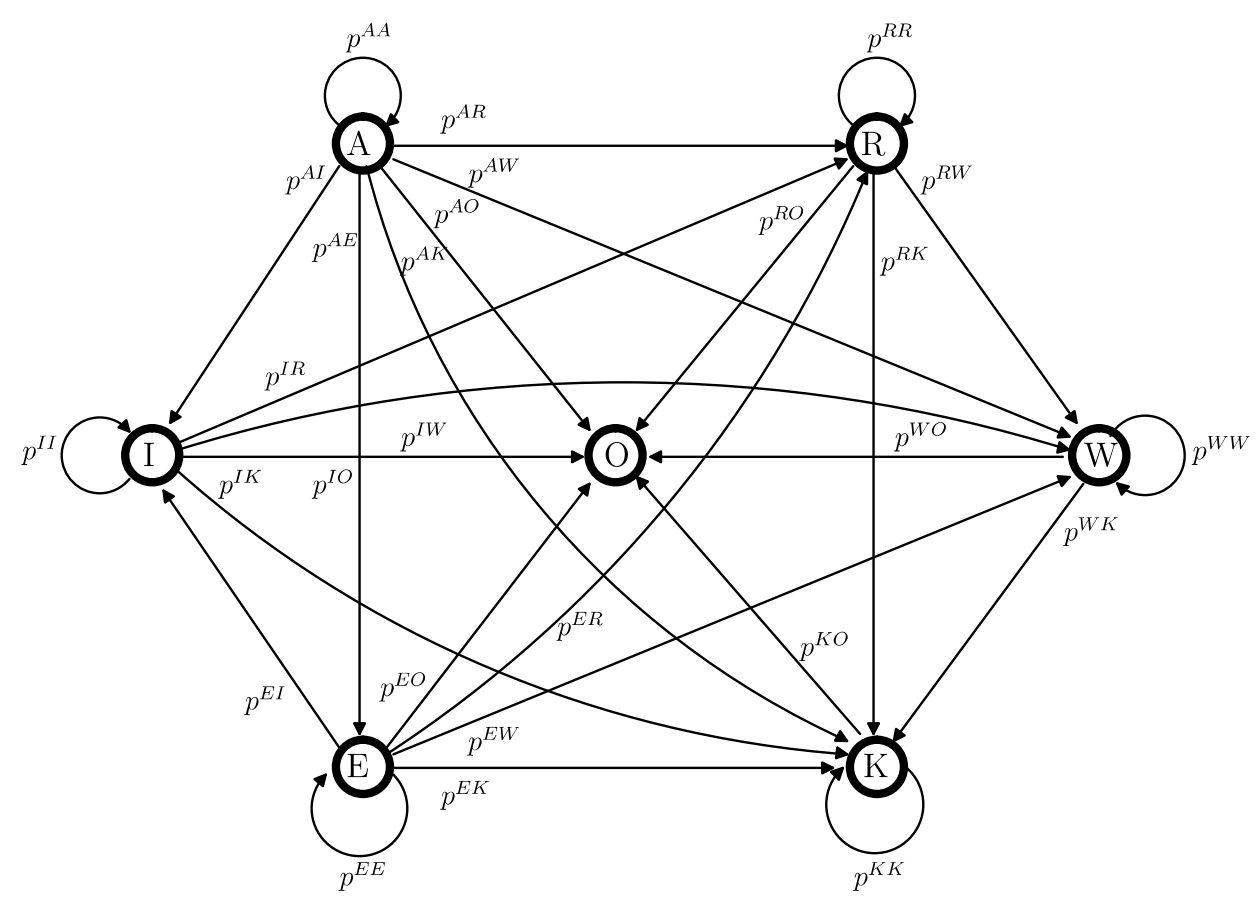

Fig. 2. Basic model, potential transitions in $t, t+1$.

sudden increases in the salaries that are due to career opportunities and seized by the insuree during his active working life, which will later effect the amount of the liabilities. ${ }^{1}$ The future evolution of the minimum return rate can be modeled with a simplified version of Eq. (1) by omitting the jump process component. For the derivation of the corresponding distribution parameters that are necessary for the discretization of this process, the authors refer for example to Karatzas and Shreve (1994).

The discretization of the resulting normally distributed parameters can be performed, e.g., by approximating the corresponding probabilities with the multinomial distribution or by using the barycentric discretization (see also Siede, 2000 or Frauendorfer, 1992). The adjacent determination of the contractual functions is then based on the usual actuarial calculus methods (see, e.g., Winklevoss, 1993 or Gerber, 1995).

\section{A regime switching model for the asset returns}

To model the future uncertainties on the asset-side, a regime switching model is proposed that incorporates a couple of empirical properties, like stochastic volatilities, fat tails, contagion, decoupling and others. The proposed regime switching approach is basically a factor model which is based on an aggregate index-based level that focuses well the needs of an institutional investor to manage the strategic asset allocation. This model has been adopted from Hamilton (1989). Its application is in line with Ang and Bekaert (1999)

\footnotetext{
${ }^{1} v$ represents the extent of the jump movement. $\mu$ is the mean reverting parameter. $\kappa$ is the speed of adaption to the mean reverting parameter.
} 
who have studied international asset allocation with stochastic correlations. The first empirical analysis was performed by Boos (2004). An extension of the application and empirical analysis for the period 1982-2006 can be found in Schwendener (2006). In order to forecast the factors - and by means of the factors also the returns - an additional set of instruments with forecasting power is considered. Similar conditional factor models can be found for example in Harvey (1995) or Oertmann (1997). The model assumes further that the continuous excess returns of the considered asset categories depend on a small number of factors $K<N$ plus in addition an idiosyncratic part. The approach presented accounts for different regimes observable on financial markets (mainly two, as described below). In the model, the regime to prevail is controlled by a Markov-process. As the derived excess returns follow a regime dependent normal distribution, the implicit distribution over both regimes is thus a mixture of normal distributions.

The corresponding factor model for the excess returns by means of the two regimes $\left(s_{t}^{i}=1,2\right)$ refers closely to Boos et al. (2004), Jacoby (2005), respectively, Schwendener (2006):

$$
\begin{aligned}
& z_{t||_{t}^{i}, p}=\xi_{p}^{s_{t}^{i}}+\eta_{p}^{s_{t}^{i}} z_{t-1, p}^{s_{t}^{i}}+\epsilon_{t, p}^{z, s_{t}^{i}}, \quad p=1, \ldots, P, \\
& x_{t \mid s_{t}^{i}, k}=\lambda_{k}^{s_{t}^{i}}+\sum_{p=1}^{P} \gamma_{p, k}^{s_{t}^{i}} z_{t-1, p}^{s_{t}^{i}}+\epsilon_{t, k}^{x, s_{t}^{i}}, \quad k=1, \ldots, K, \\
& y_{t \mid s_{t}^{i}, n}=\alpha_{n}^{s_{t}^{i}}+\sum_{k=1}^{K} \beta_{k, n}^{s_{t}^{i}} x_{t, k}+\epsilon_{t, n}^{y, s_{t}^{i}}, \quad n=1, \ldots, N,
\end{aligned}
$$

whereas the index $z_{t \mid s_{t}^{i}, p}$ represents the instruments with forecasting power, $x_{t \mid s_{t}^{i}, k}$ the common risk factors and $y_{t \mid s_{t}^{i}, n}$ the asset excess returns in continuous time. These instruments may represent, e.g., short rate, long rate, yield spread, yield spread/short rate, dividendprice ratio, dividend-earnings ratio, credit spreads, credit spreads/short rate. A central assumption of the model is, that the instruments can influence the asset returns only by means of the factors and not directly. Therefore, the differences in the expected return among the assets are originated uniquely by a different exposure to the relevant risk factors. Substituting the factors out of the third equation of (2) results in the following equation where the asset-returns depend uniquely on the instruments.

$$
y_{t \mid s_{t}^{i}, n}=\underbrace{\alpha_{n}^{s_{t}^{i}}+\sum_{k=1}^{K} \beta_{k, n}^{s_{t}^{i}} \lambda_{k}^{s_{t}^{i}}}_{\text {const., indep. of } z_{t}}+\underbrace{\sum_{k=1}^{K} \sum_{p=1}^{P} \beta_{k, n}^{s_{t}^{i}} \gamma_{t, k}^{s_{i}^{i}} z_{t-1, p}^{s_{t}^{i}}}_{\sum_{p=1}^{P} \zeta_{p, n}^{s_{t}^{i} z_{t}^{i}} z_{t-1, p}}+\underbrace{\sum_{k=1}^{K} \beta_{k, n}^{s_{t}^{i}} \epsilon_{t, k}^{x, s_{t}^{i}}+\epsilon_{t, n}^{y, s_{t}^{i}}}_{\substack{s_{t}^{i} \\ \epsilon_{t, n}}} .
$$

As a result of the assumption that the instruments are taking effect only by means of the factors, it follows that $z_{t-1, p}^{i_{t}^{i}}$ is uncorrelated with $\epsilon_{t, n}^{s_{t}^{i}}$ as well as uncorrelated with $\epsilon_{t, k}^{x, s_{t}^{i}}$. Further, $\epsilon_{t, k}^{x, s_{t}^{i}}$ and $\epsilon_{t, n}^{y, s_{t}^{i}}$ shall be uncorrelated, by what the linear model in Eq. (3) can be written as the sum of four orthogonal components:

$$
y_{t \mid s_{t}^{i}, n}=\underbrace{\alpha_{n}^{s_{t}^{i}}+\sum_{k=1}^{K} \beta_{k, n}^{s_{t}^{i}} \lambda_{k}^{s_{t}^{i}}}_{\text {I. }}+\underbrace{\sum_{p=1}^{P} s_{p, n}^{i} z_{t-1, p}^{s_{t}^{i}}}_{\text {II. }}+\underbrace{\sum_{k=1}^{K} \beta_{k, n}^{s_{t}^{i}} \epsilon_{t, k}^{x, s_{t}^{i}}}_{\text {III. }}+\underbrace{\epsilon_{t, n}^{y, s_{t}^{i}}}_{\text {IV. }} .
$$

As already stated above, the probabilities of occurrence of the above mentioned regimes $\left(s_{t}^{i}=1,2\right)$ are taken into consideration by a discrete Markov-process. In a nutshell, the two derived regimes can be described as follows: the first regime refers to the typical 
features of a bear market; in a volatile environment the correlation between equity and bonds varies from quite low to even negative values (decoupling). On the other side, a high correlation among a couple of selected equity indices can be found (contagion). Usually, bonds will perform significantly better in such an environment. On the other side, the second regime shows the typical features of a bull market: in a less volatile environment, the correlation between bonds and equity is significantly higher as in regime one. Further, contrary to regime one, a low correlation among a couple of selected equity indices is observable. Usually, shares will perform much better in such an environment. The random variable $s_{t}^{i}$ therefore follows a Markov-process with transition matrix:

$$
\begin{aligned}
P & =\left(\begin{array}{cc}
p & 1-p \\
1-q & q
\end{array}\right) \text { with } \\
p & =P\left[s_{t}^{i}=1 \mid s_{t-1}^{i}=1\right], \\
q & =P\left[s_{t}^{i}=2 \mid s_{t-1}^{i}=2\right] .
\end{aligned}
$$

Empirical tests, in particular likelihood ratio tests showed that besides the variancecovariance matrix of the factors and therefore of the asset categories all parameters are regime independent. The variance-covariance matrix of the error terms as well as the returns in the two regimes do not alter significantly from each other. The Betas vary over time, but these fluctuations are independent of the regimes (see, e.g., Schwendener, 2006). Using matrix notation the model can be stated as follows:

$$
y_{t}=\alpha+\beta^{\prime} x_{t}+\epsilon^{y}=\alpha+\beta^{\prime} \lambda+\beta^{\prime} \gamma^{\prime} z_{t-1}+\beta^{\prime} \epsilon^{x}+\epsilon^{y}
$$

whereby the expected return is given by

$$
\bar{y}_{t}=\alpha+\beta^{\prime} \lambda+\beta^{\prime} \gamma^{\prime} z_{t-1}
$$

and the variance-covariance matrix (subject to state $s_{t}^{i}$ ) by

$$
\sum_{y}^{s_{t}^{i}}=\beta^{\prime} \sum_{x}^{s_{t}^{i}} \beta+D
$$

$\sum_{x}^{s_{t}^{i}} \in \mathbb{R}^{k \times k}$ defines the variance-covariance matrix of the factors and $D$ the variancecovariance matrix of the error terms. The distribution of the excess returns (especially the variation) is therefore governed by the prevailing regime. Thus, since there is a mixture of two different normals, the model also explains for the fat tails observable on financial markets. By means of the Markov-process that governs the switches between the two regimes, the model takes also the observable volatility clusters on financial markets into account. It was shown in Boos (2004) and further investigated by Schwendener (2006) that the above drafted two regimes are sufficient to explain the major part of variation over time. The estimation of the parameters is accomplished by maximum-likelihood (see Gray (1996), Hamilton (1989) or Hamilton (1994)).

\subsection{Empirical data}

The following example based on a maximum likelihood estimation illustrates how the regime switching model captures all above-mentioned empirical features. The illustrative 
example containing monthly data covering period 1982-2006 is based on four factors and considers an international portfolio with six asset categories (see Schwendener, 2006):

Factors

EQ:

EUR:

Equity-factor

BD:

Bond-factor

Assets

$\mathrm{CHb}$ :

Euro-hedge-factor

USD:

US dollar-hedge-factor

Bonds $\mathrm{CH}$

CHa:

Equity $\mathrm{CH}$

EUb:

Bonds EU

EUa:

Equity EU

$\mathrm{USb}$ :

Bonds USA

USa:

Equity USA

Fig. 3 draws the comparison between the realized volatility and the volatility implied by the model. Hence it illustrates how the volatility clustering and therefore the regime probabilities are captured by the regime switching framework. As visible in Fig. 3 volatile regimes occur during and short after crashes in the financial markets (see, e.g., Gulko (2002)).

The risk structure of the two regimes (Table 1), which depends on the implied volatility, reveals the above-mentioned features of empirical finance.

The volatilities of stock indices indicate regime 1 as the volatile regime and emphasize the co-movement effects. Higher correlations $(\rho>0.7)$ among stock indices in regime 1 compared to regime 2 indicate the contagion phenomenon which reduces the benefits of portfolio diversification at the time investors need them most. The correlations among stocks and bonds are negative in regime 1 but positive in regime 2 confirming the decoupling of financial markets. This phenomenon denotes that bonds offer an effective portfolio diversification during turbulent stock markets (i.e., financial crisis), at the time diversification is needed most. This risk structure of the asset categories derives from the four factors which contain the same observable features. Notice, the volatility of bonds and the correlations among them are regime independent by definition.

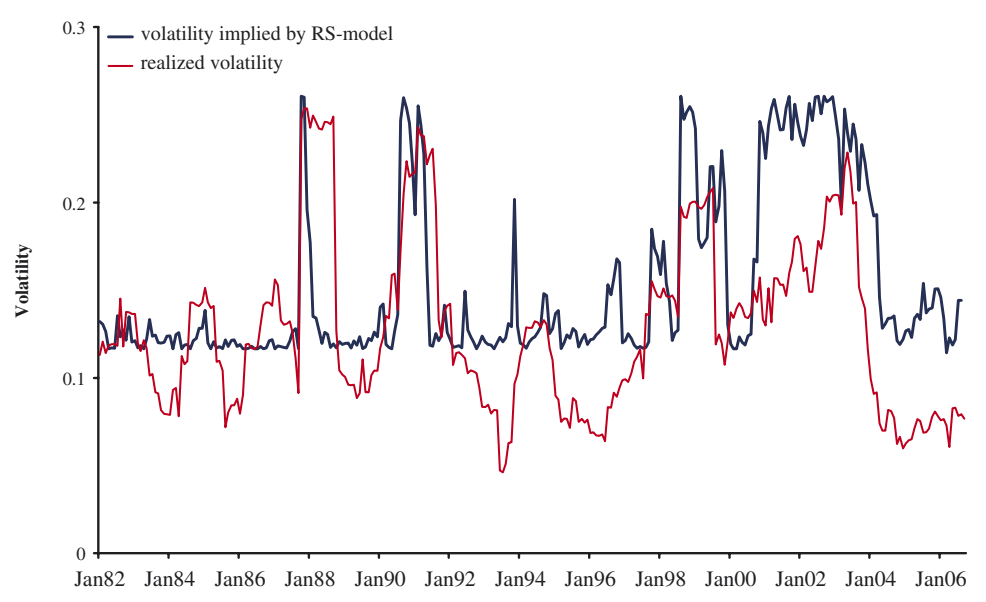

Fig. 3. Volatility-clustering. 
Table 1

Risk structure of asset categories

\begin{tabular}{|c|c|c|c|c|c|c|c|c|}
\hline Volatility & & Correlation & $\mathrm{CHb}$ & $\mathrm{EUb}$ & $\mathrm{USb}$ & $\mathrm{CHa}$ & EUa & USa \\
\hline \multicolumn{9}{|l|}{ Regime 1} \\
\hline $\mathrm{CHb}$ & $4.04 \%$ & $\mathrm{CHb}$ & 1 & 0.2728 & 0.0716 & -0.0178 & -0.1416 & -0.1149 \\
\hline EUb & $3.80 \%$ & EUb & & 1 & 0.1360 & -0.2872 & -0.2723 & -0.2338 \\
\hline USb & $11.86 \%$ & $\mathrm{USb}$ & & & 1 & 0.3695 & 0.4346 & -0.0354 \\
\hline $\mathrm{CHa}$ & $25.12 \%$ & $\mathrm{CHa}$ & & & & 1 & 0.8573 & 0.7185 \\
\hline EUa & $\mathbf{2 8 . 9 6} \%$ & EUa & & & & & 1 & 0.7434 \\
\hline USa & $22.74 \%$ & USa & & & & & & 1 \\
\hline \multicolumn{9}{|l|}{ Regime 2} \\
\hline $\mathrm{CHb}$ & $4.04 \%$ & $\mathrm{CHb}$ & 1 & 0.2728 & 0.0716 & 0.2687 & 0.0523 & 0.1496 \\
\hline EUb & $3.80 \%$ & $\mathrm{EUb}$ & & 1 & 0.1360 & 0.1152 & 0.1291 & 0.2973 \\
\hline USb & $11.86 \%$ & $\mathrm{USb}$ & & & 1 & 0.2642 & 0.4464 & -0.4049 \\
\hline $\mathrm{CHa}$ & $14.86 \%$ & $\mathrm{CHa}$ & & & & 1 & 0.5341 & 0.3081 \\
\hline EUa & $14.99 \%$ & EUa & & & & & 1 & 0.2411 \\
\hline USa & $17.65 \%$ & USa & & & & & & 1 \\
\hline
\end{tabular}

In the range of dynamic asset allocation the regime switching framework provides for the evaluation of international diversification a suitable added value. This is in line with Ang and Bekaert (1999). The above described model allows further to consider the derived liability trajectories of Section 2 as additional asset classes. These additional asset classes are needed to tackle the stochastic optimization problem in a way strategic asset allocation process allows to take the liability dynamic into account (see Section 4). As a result of the high interest rate sensitivity of pension fund obligations, it will be shown in Section 5 that the careful attention of the correlation structure between asset and liabilities, by means of the regime switching approach, will have a significant impact on the efficient asset allocation and therefore on the risk profile of the whole pension plan.

\section{Efficient asset allocation given liability}

In the model presented, all realized portfolios of the penultimate period are used to formulate the variance of final wealth. The aim is to minimize the variance of final wealth for a given expected overall return at the end of the planning horizon subject to budget equations and take variable transaction costs and a riskless cash position into account. The following section states this dynamic mean-variance problem as a multistage stochastic program.

At first, the evolution of investment decisions $x_{t}, t=0, \ldots, T+1$ over the planning horizon including $T+1$ periods is investigated (see also Frauendorfer and Siede (2000)). The initial portfolio $x_{\text {inii }}$ consists of $n$ risky assets and a cash position, which are given in money terms. The evolution of wealth takes place by periodically rebalancing the portfolio, which grows by the return one obtains through the investment. Precisely speaking, rebalancing the initial portfolio takes place by purchasing $v_{0 i}^{+} \geqslant 0$ or selling $v_{0 i}^{-}>0$ to the $i$ th risky asset. ${ }^{2}$ Further, the investment in every asset has an uncertain return

\footnotetext{
${ }^{2}$ Thus, the investment in this asset is: $X_{0 i}:=X_{\operatorname{ini} i}+v_{0 i}^{+}-v_{0 i}^{-}$.
} 
$x_{0 i}\left(r_{0 i}-1\right)$ which is firstly known at the end of the initial period. However, the distribution of $r_{0 i}$ is assumed to be known by using the presented model in Section 3 which particularly includes the correlation to the other assets. After deducting variable transaction $\operatorname{costs} c_{i}$ for selling, respectively $d_{i}$ for purchasing, we hold

$$
x_{0, n+1}:=x_{\mathrm{ini}, n+1}-\sum_{i=1}^{n}\left(1+d_{i}\right) v_{0}^{i,(+)}+\sum_{i=1}^{n}\left(1-c_{i}\right) v_{0}^{i,(-)},
$$

in cash, which is invested in a riskless asset yielding a return $x_{0 n+1}\left(r_{0 n+1}-1\right)$ known before the investment takes place. In period $1, X_{0 i} r_{0 i}, i=1, \ldots, n+1$ replaces the initial portfolio of the initial period 0 , and, again, the portfolio is rebalanced by purchasing and selling. This way, the same situation up to period $T$ is resulting, which corresponds to the budget equations

$$
\begin{aligned}
x_{t, i} & =x_{t-1, i} r_{t-1, i}+v_{t, i}^{(+)}-v_{t, i}^{(-)} \\
x_{t, n+1} & =x_{t-1, n+1} r_{t-1, n+1}-\sum_{i=1}^{n}\left(1+d_{i}\right) v_{t, i}^{(+)}+\sum_{i=1}^{n}\left(1-c_{i}\right) v_{t, i}^{(-)}
\end{aligned}
$$

for $t=1, \ldots, T$. Notice, that only the rates of transaction costs $c$ and $d$ are known in advance, which may depend on the assets in particular large-, small- or mid-cap assets. The return itself is given in the form of a stochastic process where only the conditional distribution is known. Furthermore, the policy is dependent on all previous decisions and realizations of the return process and the budget equation leads inductively to a wealth of $x_{T}^{\prime} r_{T}$ at the end of the planning horizon.

In the following, the objective is to minimize the risk of the portfolio, which is characterized by the variance of final wealth. The variance itself is determined by the return processes of the assets considered as well as by the portfolio chosen at every stage during the planning horizon. At the end of period $T$, the variance of terminal wealth is therefore

$$
\begin{aligned}
\operatorname{Var}\left(x_{T}^{\prime} r_{T}\right) & =E\left(\left(x_{T}^{\prime} r_{T}\right)^{2}\right)-\left(E\left(X_{T}^{\prime} r_{T}\right)\right)^{2} \\
& =E\left(E\left(\left(x_{T}^{\prime} r_{T}\right)^{2} \mid \mathscr{F}_{T}\right)\right)-\left(E\left(E\left(x_{T}^{\prime} r_{T} \mid \mathscr{F}_{T}\right)\right)\right)^{2}
\end{aligned}
$$

where $\left(\mathscr{F}_{t}\right)_{t=1, \ldots, T}$ is the canonical filtration induced by the multidimensional return process $\left(r_{t-1}\right)_{t=1, \ldots, T}$ on a probability space $(\Omega, \mathscr{F}, P)$, meaning $\mathscr{F}_{t}=\sigma\left(r_{s}, s<t\right)$ with $\mathscr{F}_{1} \subseteq \cdots \subseteq \mathscr{F}_{T} \subseteq \mathscr{F}$, wherewith the portfolio $x_{t}$ is $\mathscr{F}_{t}$-measurable. However, $r_{t}$ is only measurable with respect to $\mathscr{F}_{t+1}$ since only the distribution of returns is known up to time $t$ but not the realization itself.

Given the information at time $T$ and making use of the 'tower-property': $E\left(E\left(X \mid \mathscr{F}_{t}\right)\right)=E(X)$, the expected return is

$$
E\left(x_{T}^{\prime} r_{T} \mid \mathscr{F}_{T}\right)=x_{T}^{\prime} E\left(r_{T} \mid \mathscr{F}_{T}\right)=x_{T}^{\prime} \bar{r}_{T}
$$

with $\bar{r}_{T}$ denoting the conditional expectation of return during period $T$. Similarly, given $\mathscr{F}_{T}$, the variance is

$$
\operatorname{Var}\left(x_{T}^{\prime} r_{T} \mid \mathscr{F}_{T}\right)=E\left(\left(x_{T}^{\prime} r_{T}\right)^{2} \mid \mathscr{F}_{T}\right)-\left(E\left(x_{T}^{\prime} r_{T} \mid \mathscr{F}_{T}\right)\right)^{2}
$$


Let $\sigma_{T}$ denote the (conditional) variance-covariance matrix. By rearranging (13) and using (12), one obtains

$$
\begin{aligned}
E\left(\left(x_{T}^{\prime} r_{T}\right)^{2} \mid \mathscr{F}\right) & =\operatorname{Var}\left(x_{T}^{\prime} r_{T} \mid \mathscr{F}_{T}\right)+\left(E\left(x_{T}^{\prime} r_{T} \mid \mathscr{F}_{T}\right)\right)^{2}=x_{T}^{\prime} \operatorname{Var}\left[r_{T}\right] x_{T}+x_{T}^{\prime}\left(E \mid r_{T}\right)^{2} x_{T} \\
& =x_{T}^{\prime}\left(\sum_{T}+\bar{r}_{T} \bar{r}_{T}^{\prime}\right) x_{T} .
\end{aligned}
$$

Thus, by replacing (14) in (11) the variance of final wealth yields as follows:

$$
\operatorname{Var}\left(x_{T}^{\prime} r_{T}\right)=E\left(x_{T}^{\prime}\left(\sum_{T}+\bar{r}_{T} \bar{r}_{T}^{\prime}\right) x_{T}\right)-\left(E\left(x_{T}^{\prime} \bar{r}_{T}\right)\right)^{2} .
$$

This vector depends on the history of returns up to time $T$ via the budget equations, where the realizations of the returns themselves depend on their distribution. Therefore, for portfolio $x_{T}$, the information about conditional covariances is implicitly included. We further emphasize that the quadratic form in the objective function consists of a one-rank update of the conditional variance-covariance matrix. This one-rank update is represented by the diadic product of the conditional expected returns.

In the model - analogously to the Markowitz approach - an investor wishes to minimize the variance of the overall return under a set of linear constraints. These constraints firstly represent the budget equations that link one period to the next and, secondly, the requirement to fulfill the predefined expected return

$$
\mu=E\left(x_{T}^{\prime} r_{T}\right)=E\left(x_{T}^{\prime} E\left(r_{T} \mid \mathscr{F}_{T}\right)\right)=E\left(x_{T}^{\prime} \bar{r}_{T}\right)
$$

over the planning horizon (see also Frauendorfer and Siede (2000)). By assuming a discrete distribution with final support, i.e., $\Omega=\left(\Omega_{1}, \ldots, \Omega_{T}\right)$ with finite sets $\Omega_{t}, t=1, \ldots, T$, the model can be considered as a stochastic multistage programming problem with the objective of minimizing (15) with respect to the budget restrictions (10).

$$
\begin{aligned}
& \min E_{\omega^{T}}\left(x_{T}^{\prime}\left(\omega^{T}\right)\left(\sum_{T}\left(\omega^{T}\right)+\bar{r}_{T}\left(\omega^{T}\right) \bar{r}_{T}^{\prime}\left(\omega^{T}\right)\right)\right)-\left(E_{\omega^{T}}\left(x_{T}^{\prime}\left(\omega^{T}\right) \bar{r}_{T}\left(\omega^{T}\right)\right)\right)^{2} \\
& \text { subject to } x_{0}+E v_{0}=x_{\text {ini }} \\
& -G_{1}\left(\omega^{1}\right) x_{0}+x_{1}\left(\omega^{1}\right)+E v_{1}\left(\omega^{1}\right)=0 \text { a.s. } \\
& \vdots \\
& -G_{T}\left(\omega^{T}\right) x_{T-1}\left(\omega^{T-1}\right)+x_{T}\left(\omega^{T}\right)+E v_{t}\left(\omega^{T}\right)=0 \text { a.s. } \\
& E_{\omega^{T}}\left(x_{T}^{\prime}\left(\omega^{T}\right) \bar{r}_{T}\left(\omega^{T}\right)\right)=\mu \\
& v_{0} \geqslant 0 ; v_{t}\left(\omega^{t}\right) \geqslant 0 \text { a.s. for } t=1, \ldots, T
\end{aligned}
$$

with $v_{t}=\left(v_{t}^{(+)}, v_{t}^{(-)}\right)$and

$$
\begin{aligned}
& E=\left(\begin{array}{cc}
-I & +I \\
1^{\prime}+d^{\prime} & -1^{\prime}+c^{\prime}
\end{array}\right) \in \mathbb{R}^{(n+1) \times(2 n)} \\
& G_{t}\left(\omega^{t}\right)=\left(\begin{array}{ccc}
r_{t-1}^{1}\left(\omega^{t}\right) & & \\
& \ddots & \\
& & r_{t-1}^{n+1}\left(\omega^{t}\right)
\end{array}\right) \in \mathbb{R}^{(n+1) \times(n+1)} \text { for } t=1, \ldots, T,
\end{aligned}
$$


which are chosen as to comply with the budget equations considered. Furthermore, $\omega^{t}=\left(\omega_{1}, \ldots, \omega_{t}\right) \in\left(\Omega_{1} \times \cdots \times \Omega_{t}\right)$ determines the returns $r_{t-1}\left(\omega^{t}\right)$ at time $t$. To evaluate the variance-covariance matrices and the expected returns of the last period, the whole path $\omega^{T}$ is needed. Notice, that analogous to $\left(x_{t}\right)_{t=1, \ldots, T}$, the policy process $\left(v_{t}\right)_{t=1, \ldots, T}$ is nonanticipative, i.e., $v_{t}=E\left(v_{t} \mid \mathscr{F}_{t}\right)$ with respect to the filtration $\mathscr{F}_{t}, t=1, \ldots, T$. In this program, $\omega_{t}$ is considered to have a discrete distribution with a finite number of outcomes for all $t$ that resulted by discretizing an assumed continuous distribution. Additionally, further inequality conditions to set bounds to selling and/or purchasing opportunities can be set as follows:

$$
\begin{gathered}
x_{t}^{j}-\alpha \cdot \sum_{i=1}^{n+1} G_{t}\left(\omega^{t}\right) x_{t-1}^{i} \leqslant 0 \\
\ddots \\
\vdots \\
x_{t}^{1}+\cdots+x_{t}^{j}-\beta \cdot \sum_{i=1}^{n+1} G_{t}\left(\omega^{t}\right) x_{t-1}^{i} \leqslant 0
\end{gathered}
$$

whereas Eq. (18) represents such a restriction for a single asset, whereas Eq. (19) shows a restriction for a group of assets.

The model stated in (17) is designed to include one or several liabilities ${ }^{3}$ as fixated short positions in the optimization process and to consider their correlations to the asset returns accordingly. As will be shown in Section 5, the integration of stochastic liability position will have a significant impact on the asset allocation.

As most institutional investors are confronted with liabilities or threshold requirements, the model identifies for each portfolio on the efficient frontier, the profit and loss distribution and thus the shortfall probability for a predefined threshold value. Notice, that the P\&L-distribution contains fat tails and hence is suited for the calculation of several additional risk measures.

The generation of scenarios for the asset returns is accomplished by the regime switching model presented in Section 3 whereas the discretization of the resulting parameters and variance-covariance matrices is conducted by the multinomial distribution according to Siede (2000). The authors refer to Siede (2000) for a complete description of this specific discretization procedure. The resulting optimization program is solved by a particularly efficient interior point algorithm from Steinbach that exploits the specific structure of the problem (see also Steinbach (1994, 1998), Frauendorfer (1995) and Siede (2000)).

\section{An illustrative example}

The following illustrative example in this section shall show the effect on the asset allocation that stems from the incorporation of stochastic liabilities in the optimization procedure of a multistage stochastic program. The example is based on the initial portfolio displayed in Table 2 .

\footnotetext{
${ }^{3}$ For example, liability positions derived from a model as sketched in Section 2. In such a case, the resulting liability trajectories will further have to be condensed into a customized liability index in order to be taken accordingly into consideration during the scenario generation.
} 
Table 2

Initial portfolio

\begin{tabular}{llll}
\hline Initial portfolio & & Liabilities & 800 \\
\hline Cash & 200 & 'ConstMix' & \\
Bonds CHF (CHb) & 320 & \\
Bonds EUR (EUb) & 80 & \\
Bonds USD (USb) & 80 & & \\
Equity CH (CHa) & 160 & & 800 \\
Equity EU (EUa) & 80 & $\sum$ Liabilities: \\
Equity North America (USa) & 80 & & \\
$\sum$ Assets: & 1000 & & \\
\hline
\end{tabular}

Table 3

Expected returns, transaction costs

\begin{tabular}{llll}
\hline Asset category & Expected return in $\%$ & \multicolumn{2}{l}{ Transaction costs in $\%$} \\
\cline { 3 - 4 } & & Buy & Sell \\
\hline Bonds CHF (CHb) & 1.978 & 0.5 & 0.5 \\
Bonds EUR (EUb) & 2.557 & 0.5 & 0.5 \\
Bonds USD (USb) & 1.887 & 0.5 & 0.5 \\
Equity CH (CHa) & 4.327 & 0.5 & 0.5 \\
Equity EU (EUa) & 4.961 & 0.5 & 0.5 \\
Equity North America (USa) & 4.574 & 0.5 & 0.5 \\
Liability (ConstMix) & 2.837 & - & - \\
\hline
\end{tabular}

In order to better point out the facts of the optimization model presented in Section 4 and for a better understanding of the impact of liabilities, a specific liability-evolution has been chosen. ${ }^{4}$ The stochastic liability, here basically the Pictet BVG-Index,${ }^{5}$ is approximated with a synthetic composition. ${ }^{6}$ Historical data of the last 15 years have been used to estimate the parameters of the regime switching model, presented in Section 3, which is consequently used for the scenario generation. The following Table 3 shows the expected returns for assets and liability over both regimes.

Keeping in mind the task of an institutional investor, a planning horizon of 4 years has been chosen, which was divided into 3 periods of length: 6 months, 1 year and $2 \frac{1}{2}$ years. Thus, in this case, the investor has a strategic planning horizon of 4 years and revises his allocation for the first time after 6 months. Possible restrictions on the asset side were omitted in order to better point out the implications of incorporating stochastic liabilities in the optimization process. Further, to better quantify the influence of the initial portfolio, the examples were optimized with transaction costs as well as without transaction costs. The target returns ranged between $0.5 \%$ and $7.5 \%$ with steps of 10 base-points for which in each case the initial portfolio was optimized. The resulting efficient frontiers are shown in Fig. 4.

\footnotetext{
${ }^{4}$ Basically, customized liability indices as developed in Section 2 are to be considered here.

5 Pictet BVG-Indices provide a suitable benchmark for Swiss pension funds.

6 The evolvement of the liability position in Table 2 reflects in fact a synthetic replication with weights of $40 \%$ for $\mathrm{CHb}, 20 \%$ for $\mathrm{CHa}$ as well as of $10 \%$ for $\mathrm{EUb}, \mathrm{EUa}$, USb and USa each.
} 


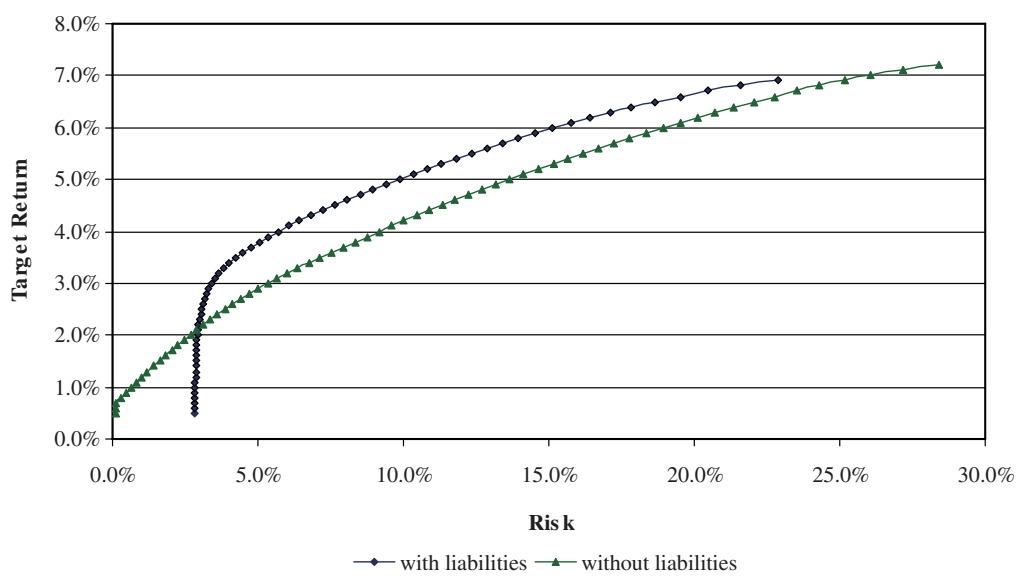

Fig. 4. Efficient frontiers, with transaction costs.

On the basis of Fig. 4 it is obvious that the resulting risk by considering stochastic liabilities is higher for small target returns while it turns out to be lower for target returns above values of $2.1 \%$. A self-evident explanation for this artefact is that for lower target returns, the risk is mainly driven by the inherent risk of the liabilities. In case of the nonexistence of liabilities, the risk turns out to be much less, as a good portion is placed in the riskless cash position. The results of Fig. 4 are reproduced in more detail in Tables 4 and 5 for some selected target returns. For the ease of exposition, the results are limited to the case without transaction costs. The case with transaction costs confirms the structural diversification. Comparing the results for the case with liabilities, respectively without liabilities, one can see that particularly the structure of the initial portfolio as well as the presence or non-presence of liabilities influence the resulting efficient allocations. Further, Tables 4 and 5 also display the shortfall risk in \% not to reach an exogenously prespecified target of 1050 .

Comparing the shortfall probabilities in Tables 4 and 5, the influence of considering the liabilities in the optimization gets visible also quite clearly: as the asset allocation is better adjusted to the stochastic properties of the liabilities, the shortfall risk as well as the risk turn out to be significantly smaller.

The accounted values for the shortfall risk can further be used as one criteria to choose the appropriate target return for the pension fund's manager. Considering the liabilities in the optimization process, the shortfall risk gets lowest for a target rate of $4.40 \%$, whereas without liabilities the shortfall risk gets lowest at a level of 5.0\%. Another interesting feature of the results is that the approach achieves to replicate quite well the structure of the stochastic liabilities for target returns between $2 \%$ and $3 \%$, i.e., for target returns that are close to the growth of the liability. Further, in the optimizations with liabilities, the proportion of equity tends to fall out higher for all target returns and provides therefore a better 'liability-adjusted' diversification. Not considering the liabilities results in a replication with unfavorable risk-return pattern and thus in a higher shortfall risk. Therefore, considering the liabilities gives a better diversification for the pension fund's manager and brings him closer to his task to secure the funding of the pension fund's liabilities. 
Table 4

Efficient portfolios, with liabilities, no transaction costs

\begin{tabular}{|c|c|c|c|c|c|c|c|c|c|c|c|c|}
\hline \multirow[t]{2}{*}{ Asset } & \multicolumn{12}{|c|}{ Target return } \\
\hline & $\begin{array}{l}\text { Initial- } \\
\text { portf. }\end{array}$ & $0.50 \%$ & $1.00 \%$ & $2.00 \%$ & $2.50 \%$ & $3.00 \%$ & $3.50 \%$ & $4.00 \%$ & $4.40 \%$ & $4.70 \%$ & $5.00 \%$ & $6.00 \%$ \\
\hline Risk (\%) & & 3.05 & 2.89 & 2.96 & 3.12 & 3.36 & 4.08 & 5.41 & 6.81 & 7.98 & 9.24 & 14.13 \\
\hline Shortfall (\%) & & 93.18 & 88.68 & 60.73 & 42.36 & 30.68 & 26.70 & 24.78 & 24.53 & 24.69 & 25.24 & 29.73 \\
\hline Cash (\%) & 20 & 36.26 & 42.05 & 19.70 & 6.96 & 0.01 & 0.01 & 0.01 & 0.01 & 0.01 & 0.01 & 0.01 \\
\hline $\mathrm{CHb}(\%)$ & 32 & 11.67 & 0.50 & 27.45 & 40.95 & 48.50 & 51.46 & 41.01 & 30.74 & 23.26 & 16.45 & 0.00 \\
\hline EUb $(\%)$ & 8 & 10.69 & 12.09 & 10.31 & 9.96 & 5.21 & 0.19 & 0.00 & 0.00 & 0.00 & 0.00 & 0.00 \\
\hline USb $(\%)$ & 8 & 10.45 & 15.20 & 8.69 & 6.60 & 5.68 & 1.04 & 0.00 & 0.00 & 0.00 & 0.00 & 0.00 \\
\hline $\mathrm{CHa}(\%)$ & 16 & 16.93 & 21.60 & 17.83 & 15.68 & 17.03 & 17.23 & 21.58 & 25.72 & 28.51 & 30.90 & 33.77 \\
\hline EUa $(\%)$ & 8 & 5.17 & 0.51 & 7.45 & 9.96 & 12.70 & 17.94 & 23.82 & 28.74 & 32.71 & 36.64 & 49.86 \\
\hline USa $(\%)$ & 8 & 8.84 & 8.05 & 8.58 & 9.89 & 10.88 & 12.14 & 13.59 & 14.80 & 15.51 & 16.00 & 16.36 \\
\hline Total (\%) & 100 & 100 & 100 & 100 & 100 & 100 & 100 & 100 & 100 & 100 & 100 & 100 \\
\hline
\end{tabular}

Table 5

Efficient portfolios, without liabilities, no transaction costs

\begin{tabular}{|c|c|c|c|c|c|c|c|c|c|c|c|c|}
\hline \multirow[t]{2}{*}{ Asset } & \multicolumn{12}{|c|}{ Target return } \\
\hline & $\begin{array}{l}\text { Initial- } \\
\text { portf. }\end{array}$ & $0.50 \%$ & $1.00 \%$ & $2.00 \%$ & $2.50 \%$ & $3.00 \%$ & $3.50 \%$ & $4.00 \%$ & $4.40 \%$ & $4.70 \%$ & $5.00 \%$ & $6.00 \%$ \\
\hline Risk (\%) & & 0.12 & 0.49 & 2.46 & 3.59 & 5.03 & 6.77 & 8.72 & 10.38 & 11.68 & 13.03 & 17.98 \\
\hline Shortfall (\%) & & 100.00 & 100.00 & 57.50 & 44.42 & 40.45 & 36.57 & 33.71 & 32.36 & 31.72 & 31.56 & 33.26 \\
\hline Cash ( $\%)$ & 20 & 95.23 & 80.65 & 6.24 & 0.01 & 0.01 & 0.01 & 0.01 & 0.01 & 0.01 & 0.01 & 0.01 \\
\hline $\mathrm{CHb}(\%)$ & 32 & 3.07 & 16.54 & 79.24 & 80.72 & 73.45 & 61.51 & 48.48 & 37.94 & 30.79 & 24.05 & 0.03 \\
\hline EUb $(\%)$ & 8 & 0.71 & 0.01 & 0.00 & 0.00 & 0.00 & 0.00 & 0.00 & 0.00 & 0.00 & 0.00 & 0.00 \\
\hline USb (\%) & 8 & 0.39 & 0.00 & 0.00 & 0.00 & 0.00 & 0.00 & 0.00 & 0.00 & 0.00 & 0.00 & 0.00 \\
\hline $\mathrm{CHa}(\%)$ & 16 & 0.22 & 0.28 & 2.59 & 4.25 & 6.82 & 12.63 & 17.68 & 22.15 & 24.88 & 27.42 & 35.96 \\
\hline EUa $(\%)$ & 8 & 0.19 & 1.46 & 6.74 & 9.69 & 12.69 & 17.85 & 23.83 & 28.96 & 32.81 & 37.02 & 50.13 \\
\hline USa $(\%)$ & 8 & 0.19 & 1.07 & 5.20 & 5.33 & 7.03 & 8.01 & 10.02 & 10.94 & 11.51 & 11.52 & 13.87 \\
\hline Total (\%) & 100 & 100 & 100 & 100 & 100 & 100 & 100 & 100 & 100 & 100 & 100 & 100 \\
\hline
\end{tabular}

\section{Conclusion}

This paper documents the transfer of the one-period MARKOwITZ-approach (see Markowitz (1952)) into a multi-period setting that also accounts for the liabilities and their stochastic interactions to the asset allocation. The presented model particularly considers for rebalancing activities, transaction costs as well as regime-dependent stochastic variancecovariance matrices. The multistage stochastic program presented also accounts for future netto-cash-flows specified by the user.

The objective function is a mean variance criterium that leads to decisions that are consistent with those of a quadratic utility maximization (see, also Siede (2000)). It is recalled that the quadratic form in the objective function consists of a one-rank update of the conditional variance-covariance matrix. This one-rank update is represented by the diadic product of the conditional expected returns. In general, the mean-variance criterium 
may be replaced by any other utility function. However, such extensions are postponed to further research.

It was also shown, that the integration of liabilities in the optimization process has a decisive impact on the shortfall probabilities as well as on the composition of the efficient portfolios. In addition, the numerical approach also provides the whole distribution information of the final wealth, respectively the final surplus and is thus a crucial decision-finding tool for every institutional investor. The results point out very clearly that a consistent modeling and integration of the liabilities is therefore indispensable in an integrated portfolio management process.

Recent investigations of the underlying portfolio selection approach with respect to long-term planning horizon and with respect to the sensitivity of the diversification subject to the estimation of asset returns may be fund in Niedermann (2006), and Heuer (2006).

\section{References}

Ang, A., Bekaert, G., 1999. International Asset Allocation with Time-Varying Correlations. Working Paper 7056, NBER.

Boos, D., 2004. Volatilität und Korrelation internationaler Kapitalmärkte. Working Paper, Institute for Operations Research and Computational Finance, University of St. Gallen, Switzerland.

Boos, D., Koller, J., Schmid, O., 2004. Dynamic Asset Allocation with Regime Shifts. Working Paper Series in Finance, University of St. Gallen, Switzerland.

Cariño, D.R., Ziemba, W.T., Formulation of the Russell-Yasuda Kasai Financial Planning Model, Operations Research, vol. 46, No. 4, July-August 1998. pp. 433-449.

Consigli, G., Dempster, M.A.H., 1998. Dynamic stochastic programming for asset-liability management. Annals of Operations Research 81, 131-162.

Drijver, S., 2005. Asset Liability Management for Pension Funds using Multistage Mixed-Integer Stochastic Programming. Labyrint Publications, Ridderkerk.

Frauendorfer, K., 1992. Stochastic Two Stage Programming. In: Lecture Notes in Economics and Mathematical Systems No. 392. Springer, Berlin.

Frauendorfer, K., 1995. The Stochastic Programming Extension of the Markowitz Approch. International Journal on Neural and Mass-Parallel Computing and Informations Systems 5, 449-460.

Frauendorfer, K., Siede, H., 2000. Portfolio Selection Using Multistage Stochastic Programming. Central European Journal of Operations Research 7, 277-289.

Gerber, H.U., 1995. Life Insurance Mathematics. Heidelberg, Berlin, New York.

Gray, S.F., 1996. An Analysis of Conditional Distribution of Interest Rates as a Regime-Switching Process. Journal of Financial Economics 42, 27-62.

Gulko, L., 2002. Decoupling. Journal of Portfolio Management 28, 59-66.

Hamilton, J.D., 1989. A new approach to the economic analysis of nonstationary time series and the business cycle. Econometrica 57 (2), 357-384.

Hamilton, J.D., 1994. Time Series Analysis. Princeton University Press, Princeton.

Harvey, C., 1995. Predictable risk and returns in emerging markets. Review of Financial Studies 8, $773-816$.

Heuer, J., 2006. Dynamische Erwartungswert-Varianz Analyse: Sensitivität der effizienten Portfolios. Bachelor Thesis, University of St. Gallen, Switzerland.

Hilli, P., Koivv, M., Pennanen, T., Ranne, A., in press. A stochastic programming model for asset and liability management of a finnish pension company. Annals of Operations Research.

Jacoby, U., 2005. Stochastische Liability-Modelle für Vorsorgeeinrichtungen. Verlag Paul Haupt, Bern, Stuttgart, Wien.

Karatzas, I., Shreve, S., 1994. Brownian Motion and Stochastic Calculus, second ed. In: Graduate Texts in Mathematics, 113 Springer.

Koller, M., 2000. Stochastische Modelle der Lebensversicherung. Verlag Springer, Berlin, Heidelberg, New York.

Markowitz, H.M., 1952. Portfolio Selection. Journal of Finance 7 (1), 77-91.

Merton, R.C., 1976. Option pricing when underlying stock returns are discontinuous. Journal of Financial Economics 3, 125-144. 
Mulvey, J.M., Shetty, B., 2004. Financial planning via multi-stage optimization. Computers and Operations Research 31, 1-20.

Mulvey, J.M., Ziemba, W.T., 1998. Asset and Liability Management Systems for Long-Term Investors: Discussion of the Issues. In: Mulvey, J.M., Ziemba, W.T. (Eds.), Worldwide Asset and Liability Modelling. Cambridge University Press, Cambridge, pp. 3-38.

Niedermann, A., 2006. Einfluss des Anlagehorizontes auf die Effizienz der strategischen Asset Allocation. Master Thesis, University of St. Gallen, Switzerland.

Oertmann, P., 1997. Global risk premia on international investments. Deutscher Universitäts-Verlag, Wiesbaden.

Pflug, G., Swietanowski, A., 2000. Asset-liability optimization for Pension Fund Management in Operations Research Proceedings 2000. Springer, pp. 124-135.

Schwendener, A., 2006. Regime-Switching Modell für die Schätzung von Marktdynamiken. Master Thesis, University of St. Gallen, Switzerland.

Siede, H., 2000. Multi-Period Portfolio Optimization - with Emphasis on an Mean-Variance Criterion. Dissertation, University of St. Gallen, Bamberg.

Steinbach, M., 1994. A structured interior point SQP method for nonlinear optimal control problems. International Series of Numerical Mathematics 115, 213-222.

Steinbach, M., 1998. Recursive direct algorithms for multistage stochastic programs in financial engineering. Operations Research, 236-245.

Winklevoss, H.E., 1993. Pension Mathematics - With Numerical Illustrations. Pennsylvania.

Zenios, S.A., Ziemba, W.T. (Eds.), 2006. Handbook of Asset and Liability Management. North Holland. 